\title{
Neurophysiological Changes in Elementary School Parents after Plant Cultivation Activity
}

\author{
Hye Sook Jang, Gyung Mee Gim, Sun-Jin Jeong, and Jae Soon Kim* \\ National Institute of Horticultural \& Herbal Science, RDA, Wanju-gun 55365, Korea
}

\begin{abstract}
This study was conducted to find out the neurophysiological changes before and after plant cultivation activity in elementary school parents. Twenty seven subjects participated in total 10 sessions (once a week) of plant cultivating activities and for each session one subject attended an individual activity and the others attended a group activity. Electroencephalography $(E E G)$ and electrocardiogram(ECG) of the subject from the individual activity type and three random subjects from the group activity type were measured before and after each session. The measurements of 7 sessions were analyzed and illustrations of brain map was obtained from the average of each electrode. As a result, the alpha and beta waves of all participants after participating in plant cultivating activities were higher than before participating in the activities, which indicates that the activities increase the activity of the brain. Absolute slow alpha wave (ASA), absolute fast alpha wave (AFA), absolute low beta wave (ALB), and absolute mid beta wave (AMB) were increased after participating in plant cultivating activities, which implies that plant cultivating activities were effective in improving physiological conditions, including stability and relaxation, as well as immersion, attention and concentration. There was no statistically significant difference between those who participated in individual activities and those who participated in group activities. However, both individual and group participants showed higher relaxation, stability and concentration rate after the plant cultivating activity. This study suggests that plant cultivating activities are effective in achieving physiological stability and relaxation and improving immersion, attention and concentration in elementary school parents.
\end{abstract}

Keywords: concentration, electrocardiogram, electroencephalographic, psychology, relaxation, stability

\section{Introduction}

People of all age groups in this diverse and complicated modern society often fail to adapt to the society or are exposed to stress that causes disorders (Davis and Emory, 1995). When this kind of stress is severe or lasts for a long time, emotional anxiety and conflicts are caused, which results in continuous tension in the autonomic nervous system including the sympathetic or parasympathetic nerves, and often causes mental and physical disorders or diseases (McKenzie-Mohr et al., 1995). Many people suffer from stress in daily life, and, in particular, parents with a child are under more stress while raising a child. Parents who experience more stress tend to show a dominant parenting style, and the more pressure

This study was supported by the 2018 Horticultural and Herbal Science Program of the National Institute of Horticultural and Herbal Science of the Rural Development Administration (PJ011376042018).

Received: August 17, 2018, Revised: August 24, 2018, Accepted: October 4, 2018

First author: Hye Sook Jang, E-mail: jhs915@korea.kr, ORCID: 0000-0003-3011-8694

*Corresponding author: Jae Soon Kim, E-mail: kimjs81@korea.kr, ORCID: 0000-0002-6529-3225

2018 by the Society for People, Plants, and Environment. This is an Open Access article distributed under the terms of the Creative Commons Attribution Non-Commercial License (http://creativecommons.org/licenses/by-nc/4.0/) which permits unrestricted non-commercial use, distribution, and reproduction in any medium, provided the original work is properly cited. 
they feel from parenting, the more negative parenting behaviors they tend to show (Bang, 2004; Shin, 1997). Their parenting behaviors have a significant impact on the personality and behaviors of children (Becker, 1964). In particular, as children in elementary school experience rapid cognitive and physical changes in their developmental stage, they are in a psychologically or mentally unstable state. They are also exposed to various stress sources in school, a new environment, other than family, and thus parenting behaviors are more important in this stage (Cho, 2006).

In this context, activities of cultivating plants have received attention as they result in inner changes in parents, and enable parents to view their parenting styles from a different point of view through the life cycle of plants (Choi and Seo, 2007). In addition, it was reported that programs for plant cultivating activities reduced the inner depression or stress of mothers of an elementary school-age child, and had a positive impact on improving their relationships with children (Hwang et al., 2007). In addition, people can fulfill their instinctive yearning for humans and nature through activities of cultivating plants, and reduce their stress through activities of making a new and creative artwork using flowers and leaves (Son et al., 2006). These experiences have a positive impact on inner changes in mothers (Matsuo, 2008), and activities of caring plants enable people to understand important interactions between plants and humans (Relf, 1990). Educational programs using plants give participants a sense of pleasure, stability, confidence and psychological satisfaction in the process, and raise their interest in and understanding of plants such as concentration and creativity, which increases their interest in activities using plants and provides positive effects (Kim, 2001). In addition, it was also reported that positive effects can be obtained only with experiences utilizing nature as well as activities of cultivating plants (Shin et al., 2007). In the study, those who had depression over a certain period of time participated in a forest healing camp for three days and two nights, and forest experiences were found to have a positive impact on their physiological stability.

Therefore, the most important thing in developing a program of plant cultivating activities is developing activities customized for participants (Lee et al., 2011). The demand for healing programs of plant cultivating activities vary depending on individuals' general characteristics such as gender, age, academic background and occupation, and the existence and types of diseases (Park et al., 2012). In line with that, it is necessary to develop and standardize programs customized for participants in order to maximize their healing effect (Park et al., 2013). Therefore, this study aimed to develop measures that can give a sense of stability to mothers of an elementary school child, reduce their stress, and ensure even those who do not have any experience easily access programs of plant cultivating activities. In addition, the physiological effects of the activities utilizing easily accessible gardening boxes were examined and analyzed to verify their effects in a scientific way and to provide basic data for the development and implementation of various and effective programs of plant cultivating activities considering the gender, age and occupation of participants.

\section{Research Methods}

\section{Selection of subjects}

To examine the effect of a plant cultivation activity on changes in the physiological conditions of parents of an elementary school student, their electroencephalography (EEG), electrocardiogram (ECG), pulse and blood pressure were measured and analyzed before and after participating in plant cultivating activities. Changes in their physiological conditions after participating in the activities were measured under the same program and conditions, and the activities were divided into two types: one-on-one activities (instructor: individual) and group activities (instructor: group). Subjects were recruited through an offline bulletin board in an elementary school located in Jeonju and were selected among parents who met the selection criteria for general brain-related studies (Lee et al., 2009; Jang et al., 2017; Son et al., 1998, 1999). A total of 27 parents were selected and they were fully informed of the purpose of this study, the content 
of the plant cultivation program, and measuring items and methods. They signed the consent form for voluntary participation. They were instructed not to drink alcohol for two days prior to the experiment, and not to drink coffee, green tea, caffeine and any beverage that might stimulate their brain or blood pressure for two hours prior to the experiment. This study was approved by the Institutional Review Board (IRB) of Jeonbuk National University Hospital (e-IRB-CUH201704023002-HE002).

\section{Laboratory environmental conditions}

The physiological conditions of the subjects including electroencephalography (EEG), electrocardiogram (ECG), and blood pressure were measured in a room in an elementary school located in Jeonju (Figure 1). The size of the gray while-walled room was as follows: length $-7.0 \mathrm{~m}$, width $-3.0 \mathrm{~m}$, and height $-2.6 \mathrm{~m}$. Illuminance at the height of the table from the floor was 700 \pm 10 lux (UT383 Mini Light Meters, Japan) on average, and the humidity and temperature of the room was $70 \pm 10 \%$ (TR-72Ui, T\&D CORP., Japan) and $25 \pm 0.5^{\circ} \mathrm{C}$ respectively. To prevent any potential factor that would affect the psychological conditions of the subjects, the soundproof music room of the school was utilized.

\section{Experimental materials and methods}

The program used in this program includes outdoor activities such as sowing and harvesting the seeds of vegetables and flowers using gardening boxes for individual plants (size: $100 \times 60 \times 45 \mathrm{~cm}, 10$ horticultural plants ${ }^{-}$seeds of green leaf lettuce and red leaf lettuce, and seedlings of lavender, rosemary, Catharanthus roseus, mint, chili pepper, tomato, etc.), and indoor activities such as self-expression activities utilizing plants and vegetables. This program was held in an outdoor space in front of the cafeteria and in an indoor space of an elementary school located in Jeonju once a week for 10 weeks for 90 minutes per session. The program was provided in a separate space for those who individually participated in one-on-one activities with an instructor and those who participated in group activities. The electroencephalography (EEG), electrocardiogram (ECG) of the subjects were measured in an indoor space of the school twice for 2 minutes before and after participating the program by activity type (one-on-one/group). One participant who participated in one-on-one activities and the three persons randomly selected from those who participated in group activities were measured simultaneously. The measured results of 7 sessions, excluding the sessions of which results were measured inaccurately, were analyzed (Figure 1).

Before and after measuring the EEG and ECG of the subjects, their blood pressure and pulse were measured using a

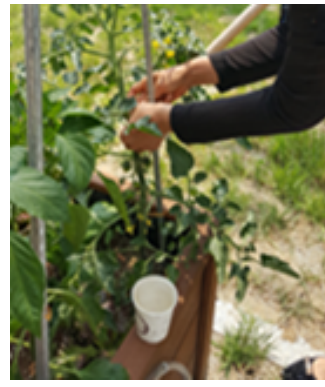

(A)

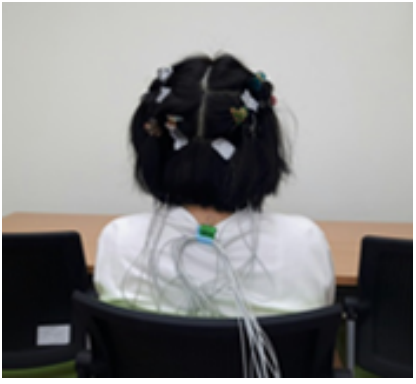

(B)

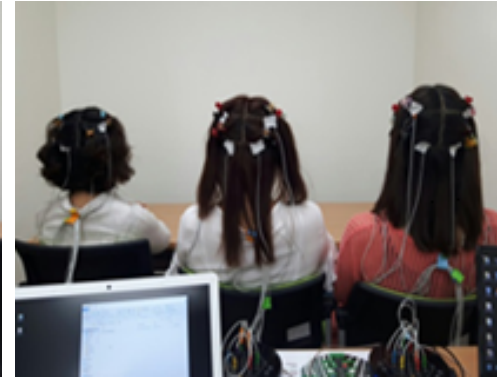

(C)

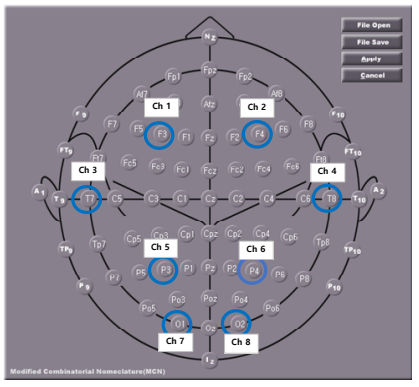

(D)

Figure 1. Plants-cultivating activity $(A)$ and electroencephalography device used in this study for the subject from the individual activity(B) and three subjects from the group activity(C). Top view of electrodes positions on the scalp(D) in electroencephalography. 
portable digital blood pressure monitor (HEM-1000, OMRON, Japan) that uses an oscilloscope. Their EEG and ECG were measured using the method suggested by Jang et al. (2017) after adjusting it to the conditions of this experiment. The monitor used in this study (BIOS-S24, BioBrain Inc., Daejeon, Korea) can monitor EEG and ECG simultaneously, and was placed $30 \mathrm{~cm}$ behind the subject. Once the subjects entered the room for measuring EEG, they were informed of the overall information of this experiment, and signed the consent form for participation. While electrodes were attached to their body, it was ensured that they feel comfortable with the indoor environment. EEG was measured according to the internationally recognized 10-20 system (Berger, 1929), and the measured spots were named according to their location on the cerebral hemispheres as follows: F (frontal lobes), T (temporal lobes), P (parietal lobes) and O (occipital lobes). Odd numbers mean the left hemisphere, and even numbers mean the right hemisphere. Gold-coated disc electrodes were attached on 8 channels on the scalp of the frontal lobes (F3, F4), temporal lobes (T3, T4), parietal lobes (P3, P4), and occipital lobes (O1, O2), and they were placed after wiping the scalp to remove dirt and applying conductive gel (Elefix z-401ce, 2016, Nihon Kohden, Japan) in order to minimize contact resistance with the skin. Reference and ground electrodes were attached behind the ears, and a total of 12 disposable electrodes were attached individually below the left chest and above the right chest (Figure 1). After that, the subjects were instructed to wear earplugs to prevent them from being exposed to the extraneous noise. For the first 3 minutes before measuring, they were allowed to relax (Figure 1).

\section{Composition of the plant cultivation program}

The plant cultivation program in this study was led by general coordinators (one person majored in agricultural education, and one person majored in horticulture), one professional instructor (main instructor: Grade I Horticultural Therapist certified by the Korea Horticultural Therapy and Wellbeing Association (KHTA), nurse assistance in Jeonbuk, social worker certified by the Ministry of Health, Welfare and Family Affairs), one main assistant (Horticultural Therapist Registered for Wellbeing certified by the KHTA) and four assistant instructors (majored in horticulture, forestry, child counseling and family studies). Each session was differentiated, and the program used in this study was the one that was provided by Jang et al. (2018) (Table 1).

In the first session, information on the overall direction of the 10 sessions and materials used in gardening boxes. The

Table 1. Plant cultivating activities applied to the subjects

\begin{tabular}{cl}
\hline Session & \multicolumn{1}{c}{ Plant cultivating activities } \\
\hline 1 & The first meeting; learning about method for cultivating crops and sowing vegetable seeds \\
2 & Planting vegetables, herbs, flowering plants seedlings and making plant tags \\
3 & Thinning plants, transplanting, removing side shoots, and installing supports \\
4 & Learning natural enemies of insect and making natural pest deterrent with egg yolk oil and egg shell calcium \\
5 & Making useful eco-friendly compost with earthworms \\
6 & Harvesting leafy vegetable and making Bibimbap \\
7 & Removing weeds, cleaning up the garden, and sharing information about nutrients and benefits of each color from vegetables \\
8 & and fruits \\
9 & Lriting a letter on pressed flower cards and harvesting herbs \\
10 & Having a garden party with products and the harvest \\
\hline
\end{tabular}


subjects were provided with education using audiovisual materials on the species and characteristics of leafy vegetables, the species of plants to be planted and planting methods. After that, the subjects designed the composition of plants for gardening boxes, mixed soil and sowed seeds. In the second session, seedlings of lettuce, chili pepper, tomato, lavender, rosemary and Catharanthus roseus were planted, and signs were decorated. In the third session, sowed plants were thinned and transplanted, and the extra sprouts of chili pepper and tomato were removed. Plants that need supporting rods were identified, and rods for chili pepper and tomato were placed. In the fourth session, the subjects had time to learn insects and natural enemies, and made egg yolk oil, an eco-friendly pesticide, and eggshell calcium, a natural nutritional supplement to prevent diseases and insect pests in the gardening boxes. In the fifth session, eco-friendly compost was made using thinned-out leaves from the plants, food waste and earthworms for the next session. In the sixth session, the extra sprouts of fruit vegetables including tomato and chili pepper were removed, and they were tied with rods again. Leafy vegetables that were cultivated in previous sessions were harvested to make and share Bibimbap with other participants. In the seventh session, plants in gardening boxes were thinned out, and weeds were removed. Vegetables that can be used for color-food artworks were collected. Using the harvested vegetables and those that were additionally purchased, color-food artworks were created, and information on the nutritions of vegetables and fruits by color, ways to eat them and their efficacy were shared with the subjects. In the eighth session, herbs that had been grown in gardening boxes for the past seven sessions were harvested and pressed to make letter paper. In the ninth session, the subjects were informed of ways to aquaculture root vegetables indoor using hydro culture soil, and ways to maintain based on their unique characteristics, and planted them. In the tenth session, the leafy lettuce, herbs, chili pepper and tomato that had been cultivated in the previous sessions were selected and shared with other participants. The subjects discuss the advantages and disadvantages of plant cultivating activities using gardening boxes, and shared their feelings with others (Jang et al., 2018).

\section{Statistical analysis}

Statistical analysis in this study was conducted using IBM SPSS ver. 25.0. The electroencephalography (EEG) and electrocardiogram (ECG) of the subjects were analyzed using a t-test and Whitney $U$ test, and their blood pressure and pulse were analyzed using a t-test. Their sociodemographic characteristics were analyzed using frequency analysis. Physiological signals were analyzed by obtaining the power spectrum of each frequency band from the measured results of EEG using the FFT (fast fourier transformation) algorithm. In addition, the generated amount of each electrode of EEG was standardized as an average, and, based on this, the average of each electrode was obtained to make a brain map. To show changes in electric energy, band areas of low electric potential on the brain map were colored in blue and band areas with high electric potential were colored in red (Figures 3-5).

\section{Results and Discussion}

\section{Sociodemographic characteristics}

The average age of the entire subjects (27 female parents) was 39.15 \pm 3.5 years. The share of those in their $30 \mathrm{~s}$ and $40 \mathrm{~s}$ was $57.7 \%$ and $42.3 \%$ respectively. The share of those who were full-time housewives was $66.7 \%$, followed by those who work in a professional field (14.8\%), others (7.4\%), those who were self-employed (7.4\%), and those who worked in services industries (3.7\%). Those whose average monthly household income was over 4 million won accounted for $66.7 \%$, followed by 3.01-4 million won (22.2\%), 2.51-3 million won (7.4\%), and 1.01-1.5 million won (3.7\%). The share 
Table 2. Characteristics of participants

\begin{tabular}{lccc}
\hline Variable & Categories & Frequency & Percent $(\%)$ \\
\hline \multirow{2}{*}{ Gender } & Male & 0 & 0 \\
& Female & 27 & 100.0 \\
Age & $30-39$ & 16 & 57.7 \\
& $40-49$ & 11 & 42.3 \\
& Housewife & 18 & 66.7 \\
Occupation & Professional & 4 & 14.8 \\
& Self-employed & 2 & 7.4 \\
& Others & 2 & 7.4 \\
Monthly household income & Service & 1 & 3.7 \\
(Won) & More than 4,000,000 & 18 & 66.7 \\
& $3,010,000 \sim 4,000,000$ & 6 & 22.2 \\
& $2,510,000 \sim 3,000,000$ & 2 & 7.4 \\
Education & Less than 2,500,000 & 1 & 3.7 \\
& Graduate school & 1 & 3.7 \\
& University & 11 & 40.7 \\
\hline
\end{tabular}

of those who graduated from graduate school, 4-year college, 2-year college and high school was 3.7\%, 40.7\%, 33.3\% and $22.2 \%$ respectively (Table 2 ).

\section{Changes in the brain waves of participants after plant cultivating activities}

Changes in the physiological conditions of the entire participants such as electroencephalography (EEG) and electrocardiogram (ECG) after participating in plant cultivating activities were measured (Tables 3 and 4, Figures 1 and 2). It was found that the absolute slow alpha wave (ASA) and absolute fast alpha wave (AFA) of the participants increased in the frontal lobes (F3, F4) that control overall cognitive skills and brain functions after participating in the activity. In addition, absolute low beta wave (ALB), an indicator of attention that accompanies arousal was high in the right frontal lobe (F4), and absolute mid beta wave (AMB), an indicator of concentration that accompanies slight tension was high in all the 8 channels measured in this study including the frontal lobes (F3, F4), temporal lobes (T3, T4), parietal lobes (P3, P4) and occipital lobes $(\mathrm{O} 1, \mathrm{O} 2)$ after participating in the activity. Participating in the plant cultivating activities was found to be effective in increasing attention and concentration, accompanying slight tension. The results were statistically significant ( $p<.05$ ) (Tables 3 and 4, Figure 2), and can be interpreted that the program was effective in not only achieving stability and relaxation and but also improving immersion, attention and concentration. The results coincide with the findings of Jang et al. (2017) that relative slow alpha wave (RSA) after doing plant-related activities was higher in most of the measured spots than that after doing IT activities (writing a document), which indicates that plant-related activities hardly accompany stress, but are effective in achieving stability and relaxation. However, absolute high beta wave (AHB), an indicator of concentration that accompanies tension and slight anxiety, after participating in the activities was statistically significantly high in the right frontal lobe, temporal lobes, parietal 
lobes and left occipital lobe $(p<.05)$, which can be attributed to the increased activity of the frontal lobes that control advanced cognitive and mental functions and the increased activity of the parietal lobes and occipital lobes that control vision. As a result, activities of cultivating plants are effective in achieving physiological stability and relaxation and

Table 3. Significance on the differences of brain waves in all participants before/after plant cultivating activity

\begin{tabular}{lcccccccc}
\hline EEG $^{z}$ & $\mathrm{~F}^{\mathrm{y}}$ & $\mathrm{F} 4$ & $\mathrm{~T} 3$ & $\mathrm{~T} 4$ & $\mathrm{P} 3$ & $\mathrm{P} 4$ & $\mathrm{O} 1$ & $\mathrm{O} 2$ \\
\hline AT & -0.937 & -1.123 & -0.884 & -0.902 & -0.943 & -0.907 & -0.892 & -0.916 \\
ASA & $-2.086^{*}$ & $-2.584^{*}$ & -1.830 & -1.767 & $-2.338^{*}$ & $-2.330^{*}$ & $-2.118^{*}$ & -2.003 \\
AFA & -1.996 & $2.361^{*}$ & -1.531 & -1.675 & -1.927 & -1.513 & -1.692 & -1.399 \\
SEF50 & 1.388 & 0.660 & -0.317 & 0.133 & 0.210 & -0.169 & 0.790 & 0.429 \\
ALB & -1.834 & $-2.369^{*}$ & -1.662 & -1.556 & -1.655 & -1.544 & -1.223 & -1.188 \\
AMB & $-4.373^{* * *}$ & $-3.589^{* * *}$ & $-3.418^{* * *}$ & $-3.619^{* *}$ & $-3.803^{* *}$ & $-4.330^{* * *}$ & $-2.601^{*}$ & $-3.104^{* * *}$ \\
AHB & -1.969 & $-2.146^{*}$ & $-3.066^{*}$ & $-2.794^{*}$ & $-3.422^{*}$ & $-2.595^{*}$ & $-2.445^{*}$ & -1.608 \\
SEF90 & 0.221 & 0.505 & 0.008 & 0.105 & -0.037 & -0.378 & 0.266 & -0.012 \\
\hline
\end{tabular}

${ }^{7}$ EEG=Electroencephalography; AT=Absolute Theta Power Spectrum; ASA=Absolute Slow Alpha Power Spectrum; AFA=Absolute Fast Alpha Power Spectrum; ALB=Absolute Low Beta Power Spectrum; AMB=Absolute Mid Beta Power Spectrum; AHB=Absolute High Beta Power Spectrum; SEF50=Spectral Edge Frequency 50\%; SEF90=Spectral Edge Frequency 90\%; Unit: AT, ASA, AFA, ALB, AMB, AHB: $\mu \mathrm{N}^{2}$; SEF50, SEF90: Hz

${ }^{\mathrm{y}}$ See Figure 1. $\mathrm{F}=$ frontal lobes; $\mathrm{T}=$ temporal lobe; $\mathrm{P}=$ parietal lobes; $\mathrm{O}=$ occipital lobes; odd and even numbers indicate left and right hemispheres, respectively.

Significant at ${ }^{*} p<.05,{ }^{* *} p<.01$ by paired t-test.

Table 4. Brain waves of all participants before/after plant cultivating activity

\begin{tabular}{llrrrrrrrr}
\hline EEG $^{\mathrm{z}}$ & Treatment & \multicolumn{1}{c}{$\mathrm{F}^{\mathrm{y}}$} & \multicolumn{1}{c}{$\mathrm{F} 4$} & \multicolumn{1}{c}{$\mathrm{T} 3$} & \multicolumn{1}{c}{$\mathrm{T} 4$} & \multicolumn{1}{c}{$\mathrm{P} 3$} & \multicolumn{1}{c}{$\mathrm{P} 4$} & O1 & O2 \\
\cline { 3 - 9 } AT & Before & $26.544 \pm 34.39^{\mathrm{x}}$ & $24.931 \pm 32.60$ & $21.787 \pm 32.95$ & $19.860 \pm 33.82$ & $25.599 \pm 35.52$ & $23.966 \pm 35.79$ & $21.779 \pm 32.57$ & $19.493 \pm 30.17$ \\
& After & $39.559 \pm 64.17$ & $40.345 \pm 64.66$ & $33.943 \pm 63.82$ & $32.325 \pm 64.17$ & $38.937 \pm 65.22$ & $36.815 \pm 65.12$ & $33.988 \pm 63.52$ & $31.850 \pm 64.23$ \\
\multirow{2}{*}{ ASA } & Before & $27.206 \pm 21.48$ & $24.464 \pm 22.89$ & $17.079 \pm 12.510$ & $14.412 \pm 11.27$ & $30.611 \pm 22.92$ & $26.465 \pm 20.97$ & $26.711 \pm 19.83$ & $21.831 \pm 15.37$ \\
& After & $36.705 \pm 36.14$ & $37.992 \pm 39.99$ & $25.082 \pm 28.163$ & $22.072 \pm 25.47$ & $42.925 \pm 41.22$ & $37.465 \pm 36.99$ & $36.896 \pm 37.51$ & $30.501 \pm 32.79$ \\
\multirow{2}{*}{ AFA } & Before & $6.173 \pm 3.75$ & $5.670 \pm 3.91$ & $5.317 \pm 3.12$ & $4.624 \pm 2.66$ & $9.486 \pm 6.77$ & $9.737 \pm 9.75$ & $9.603 \pm 10.01$ & $8.891 \pm 9.41$ \\
& After & $8.870 \pm 9.58$ & $8.989 \pm 10.61$ & $7.414 \pm 8.56$ & $6.723 \pm 7.74$ & $12.512 \pm 11.52$ & $12.158 \pm 12.80$ & $12.264 \pm 12.73$ & $10.949 \pm 12.34$ \\
\multirow{2}{*}{ SEF50 } & Before & $10.547 \pm 2.74$ & $10.863 \pm 3.13$ & $10.511 \pm 1.94$ & $11.124 \pm 2.58$ & $10.307 \pm 1.54$ & $10.357 \pm 1.67$ & $10.641 \pm 2.16$ & $10.933 \pm 2.76$ \\
& After & $10.131 \pm 2.10$ & $10.606 \pm 3.41$ & $10.642 \pm 2.60$ & $11.051 \pm 2.74$ & $10.245 \pm 1.67$ & $10.427 \pm 1.84$ & $10.383 \pm 2.17$ & $10.738 \pm 2.44$ \\
\multirow{2}{*}{ ALB } & Before & $5.883 \pm 2.78$ & $5.633 \pm 2.62$ & $5.174 \pm 2.30$ & $4.760 \pm 2.14$ & $7.569 \pm 4.09$ & $7.306 \pm 4.63$ & $6.978 \pm 4.98$ & $6.396 \pm 4.56$ \\
& After & $8.352 \pm 8.08$ & $8.557 \pm 8.14$ & $7.461 \pm 8.01$ & $6.727 \pm 7.16$ & $10.077 \pm 9.63$ & $9.354 \pm 8.32$ & $8.849 \pm 9.58$ & $7.782 \pm 7.84$ \\
\hline \multirow{2}{*}{ AMB } & Before & $8.270 \pm 3.25$ & $8.115 \pm 3.53$ & $6.550 \pm 2.84$ & $5.931 \pm 2.42$ & $8.987 \pm 4.14$ & $8.036 \pm 3.34$ & $6.815 \pm 2.87$ & $6.385 \pm 3.02$ \\
& After & $10.730 \pm 5.43$ & $11.377 \pm 6.67$ & $8.429 \pm 4.06$ & $7.873 \pm 4.09$ & $12.093 \pm 6.88$ & $10.749 \pm 5.18$ & $8.454 \pm 4.68$ & $7.810 \pm 3.76$ \\
\hline \multirow{2}{*}{ AHB } & Before & $9.145 \pm 5.60$ & $10.005 \pm 8.77$ & $6.202 \pm 2.23$ & $5.965 \pm 2.13$ & $8.055 \pm 2.93$ & $7.476 \pm 2.73$ & $6.700 \pm 2.51$ & $7.127 \pm 4.50$ \\
& After & $10.435 \pm 7.41$ & $13.357 \pm 14.87$ & $7.688 \pm 3.88$ & $7.613 \pm 4.38$ & $9.520 \pm 4.28$ & $9.734 \pm 6.27$ & $7.918 \pm 3.70$ & $8.216 \pm 4.37$ \\
\hline \multirow{2}{*}{ SEF90 } & Before & $32.481 \pm 5.53$ & $33.182 \pm 5.41$ & $33.149 \pm 4.88$ & $34.198 \pm 5.63$ & $29.499 \pm 3.94$ & $30.130 \pm 4.99$ & $31.381 \pm 5.99$ & $33.017 \pm 6.27$ \\
& After & $32.189 \pm 5.65$ & $32.457 \pm 6.54$ & $33.139 \pm 6.35$ & $34.036 \pm 6.74$ & $29.538 \pm 5.73$ & $30.618 \pm 6.34$ & $31.116 \pm 6.48$ & $33.033 \pm 6.82$ \\
\hline
\end{tabular}

${ }^{\mathrm{z}}$ EEG=Electroencephalography; AT=Absolute Theta Power Spectrum; ASA=Absolute Slow Alpha Power Spectrum; AFA=Absolute Fast Alpha Power Spectrum; ALB=Absolute Low Beta Power Spectrum; AMB=Absolute Mid Beta Power Spectrum; AHB=Absolute High Beta Power Spectrum; SEF50=Spectral Edge Frequency 50\%; SEF90=Spectral Edge Frequency 90\%; Unit: AT, ASA, AFA, ALB, AMB, AHB: $\mu \mathrm{V} 2$; SEF50, SEF90: Hz

${ }^{\mathrm{y}}$ See Figure 1. $\mathrm{F}=$ frontal lobes; $\mathrm{T}=$ temporal lobe; $\mathrm{P}=$ parietal lobes; $\mathrm{O}=\mathrm{occipital}$ lobes; odd and even numbers indicate left and right hemispheres, respectively.

${ }^{\mathrm{x}}$ Mean \pm standard deviation. 


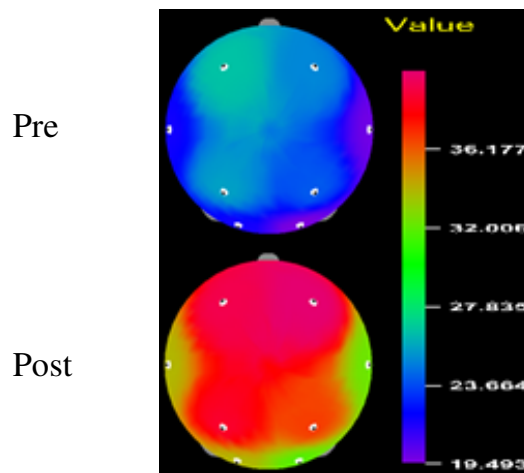

AT

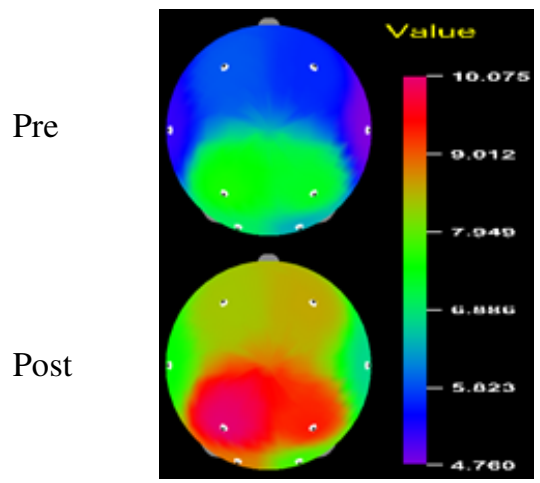

ALB

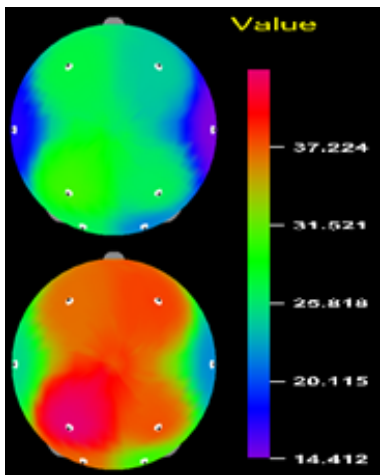

ASA

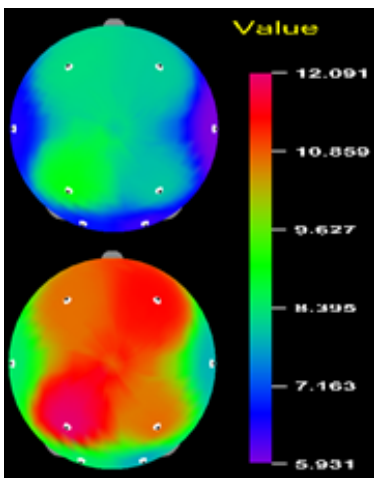

AMB

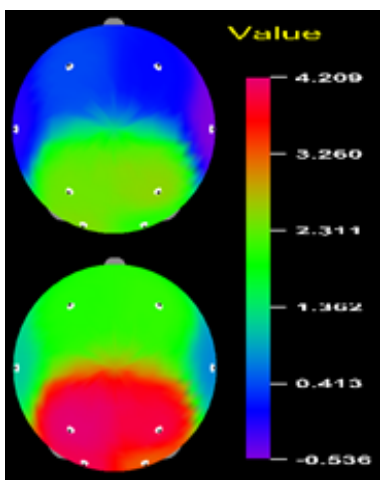

AFA

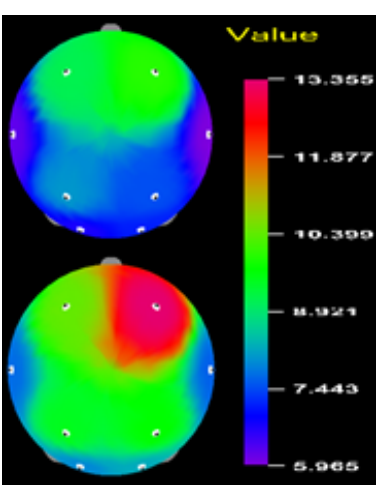

AHB

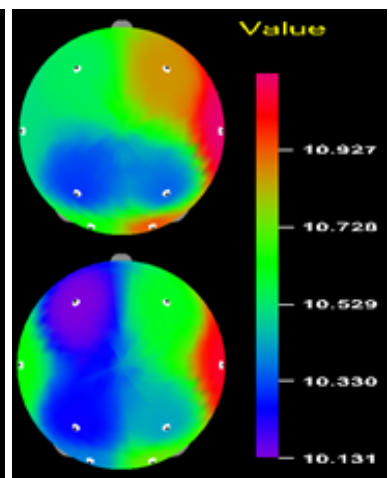

SEF50

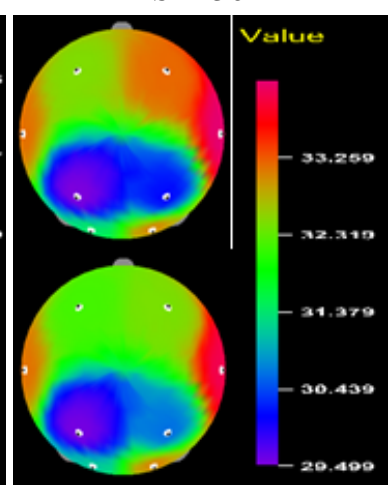

SEF90

Figure 2. Illustrations of Electroencephalography(EEG) brain mapping for all participants before and after plant cultivating activity. Blue and red indicate low and high electrical potential, respectively. Pre: Value before plant cultivating activity; Post: Value after plant cultivating activity; AT=Absolute Theta Power Spectrum; ASA=Absolute Slow Alpha Power Spectrum; AFA=Absolute Fast Alpha Power Spectrum; ALB=Absolute Low

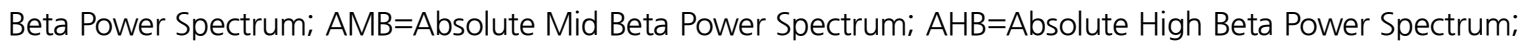
SEF50=Spectral Edge Frequency 50\%; SEF90=Spectral Edge Frequency 90\%; Unit: AT, ASA, AFA, ALB, AMB, AHB: $\mu \mathrm{V}^{2}$; SEF50, SEF90: Hz.

improving immersion, attention and concentration in a proper arousal state, and the increased attention and concentration through activities of touching and feeling plants allowed participants to actively acquire information on things and significantly improved their concentration. At the same time, however, these active brain activities accompanied tension (Tables 3 and 4, Figure 2). These results are supported by those of earlier studies including Kaplan (2001) that reported that horticultural activities or plants reduced the stress level of subjects and maintained their tranquility; Ulrich (1984) that found that they are effective in healing psychology and improving resilience; and Jang et al. (2018) that reported that stress was found to be significantly reduced in the results of saliva cortisol analysis after participating in activities of cultivating plants.

\section{Changes in the brain waves of participants by activity type (one-on-one vs group)}

Changes in the brain waves of participants by the type of plant cultivating activities (one-on-one vs group) were observed, and there was no statistically significant difference between those who participated in one-on-one activities and those who participated in group activities (Tables 5 and 8, Figure 3). The absolute theta wave (AT), absolute slow alpha wave (ASA), absolute fast alpha wave (AFA), absolute low beta wave (ALB) and absolute mid beta wave (AMB) of the 
Table 5. Significance on the differences of brain waves between individual activity participant and group activity participants before/after plant cultivating activity

\begin{tabular}{lcccccccc}
\hline EEG $^{\mathrm{z}}$ & $\mathrm{F}^{\mathrm{y}}$ & $\mathrm{F} 4$ & $\mathrm{~T} 3$ & $\mathrm{~T} 4$ & $\mathrm{P} 3$ & $\mathrm{P} 4$ & $\mathrm{O} 1$ & $\mathrm{O} 2$ \\
\hline AT & $-0.407^{\mathrm{NS}}$ & $-0.458^{\mathrm{NS}}$ & $-0.610^{\mathrm{NS}}$ & $-0.356^{\mathrm{NS}}$ & $-0.203^{\mathrm{NS}}$ & $-0.305^{\mathrm{NS}}$ & $-0.254^{\mathrm{NS}}$ & $-0.458^{\mathrm{NS}}$ \\
ASA & $-0.661^{\mathrm{NS}}$ & $-0.102^{\mathrm{NS}}$ & $-0.305^{\mathrm{NS}}$ & $-0.051^{\mathrm{NS}}$ & $-0.102^{\mathrm{NS}}$ & $-0.407^{\mathrm{NS}}$ & $-0.203^{\mathrm{NS}}$ & $-0.661^{\mathrm{NS}}$ \\
AFA & $-0.356^{\mathrm{NS}}$ & $-0.203^{\mathrm{NS}}$ & $-0.712^{\mathrm{NS}}$ & $-0.356^{\mathrm{NS}}$ & $-0.102^{\mathrm{NS}}$ & $-0.865^{\mathrm{NS}}$ & $-0.915^{\mathrm{NS}}$ & $-1.221^{\mathrm{NS}}$ \\
SEF50 & $-0.254^{\mathrm{NS}}$ & $-0.788^{\mathrm{NS}}$ & $-0.458^{\mathrm{NS}}$ & $-0.305^{\mathrm{NS}}$ & $-0.560^{\mathrm{NS}}$ & $-0.661^{\mathrm{NS}}$ & $-0.534^{\mathrm{NS}}$ & $-1.399^{\mathrm{NS}}$ \\
ALB & $-0.051^{\mathrm{NS}}$ & $-0.051^{\mathrm{NS}}$ & $-0.458^{\mathrm{NS}}$ & $-0.458^{\mathrm{NS}}$ & $-0.407^{\mathrm{NS}}$ & $-0.407^{\mathrm{NS}}$ & $-0.407^{\mathrm{NS}}$ & $-1.526^{\mathrm{NS}}$ \\
AMB & $-0.712^{\mathrm{NS}}$ & $-0.051^{\mathrm{NS}}$ & $-1.221^{\mathrm{NS}}$ & $-0.407^{\mathrm{NS}}$ & $-0.763^{\mathrm{NS}}$ & $-0.559^{\mathrm{NS}}$ & $-0.153^{\mathrm{NS}}$ & $-1.170^{\mathrm{NS}}$ \\
AHB & $-0.407^{\mathrm{NS}}$ & $-0.153^{\mathrm{NS}}$ & $-0.865^{\mathrm{NS}}$ & $-0.610^{\mathrm{NS}}$ & $-0.051^{\mathrm{NS}}$ & $-0.661^{\mathrm{NS}}$ & $-0.915^{\mathrm{NS}}$ & $-1.526^{\mathrm{NS}}$ \\
SEF90 & $-1.526^{\mathrm{NS}}$ & $-0.305^{\mathrm{NS}}$ & $-0.051^{\mathrm{NS}}$ & $-0.509^{\mathrm{NS}}$ & $-0.203^{\mathrm{NS}}$ & $-0.254^{\mathrm{NS}}$ & $-0.458^{\mathrm{NS}}$ & $-1.170^{\mathrm{NS}}$ \\
\hline
\end{tabular}

${ }^{2}$ EEG=Electroencephalography; AT=Absolute Theta Power Spectrum; ASA=Absolute Slow Alpha Power Spectrum; AFA=Absolute Fast Alpha Power Spectrum; ALB=Absolute Low Beta Power Spectrum; AMB=Absolute Mid Beta Power Spectrum; AHB=Absolute High Beta Power Spectrum; SEF50=Spectral Edge Frequency 50\%; SEF90=Spectral Edge Frequency 90\%; Unit: AT, ASA, AFA, ALB, AMB, AHB: $\mu \mathrm{N}^{2} ;$ SEF50, SEF90: $\mathrm{Hz}$

${ }^{\mathrm{y}}$ See Figure 1. F=frontal lobes; $\mathrm{T}=$ temporal lobe; $\mathrm{P}=$ parietal lobes; $\mathrm{O}=$ occipital lobes; odd and even numbers indicate left and right hemispheres, respectively.

${ }^{\mathrm{NS}}$ non-significant by Mann-Whitney U test.

A

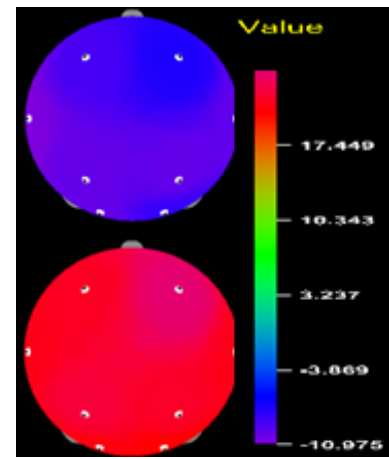

AT

A

B

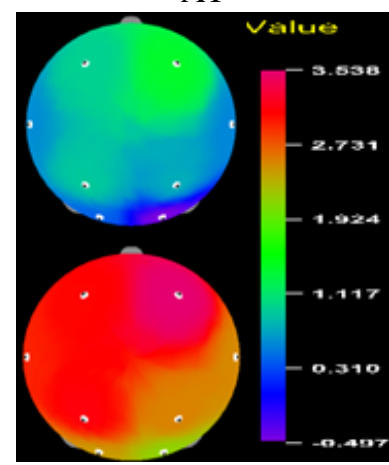

ALB

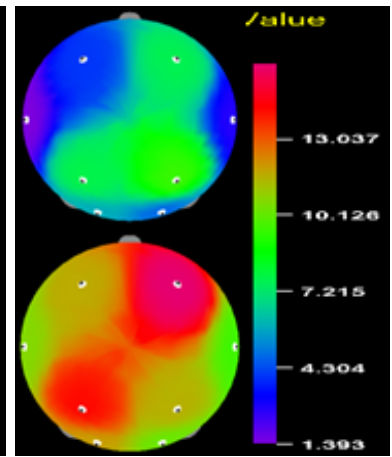

ASA

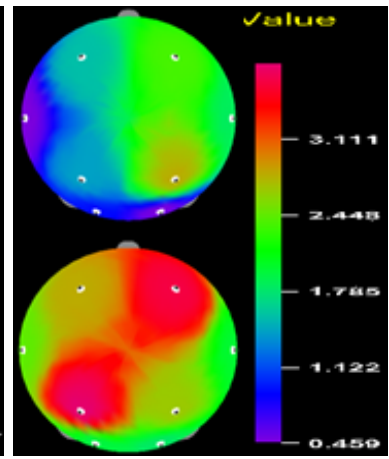

AMB

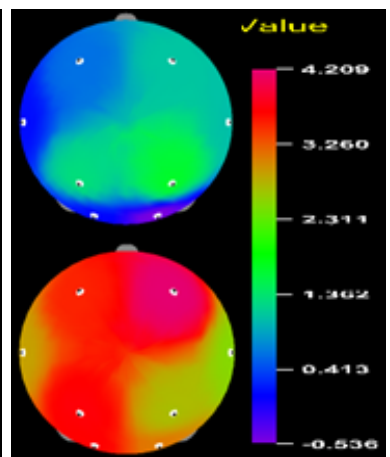

AFA

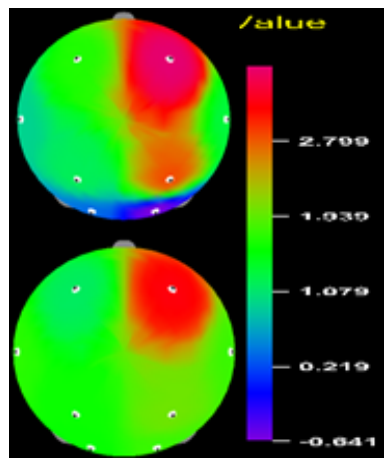

AHB

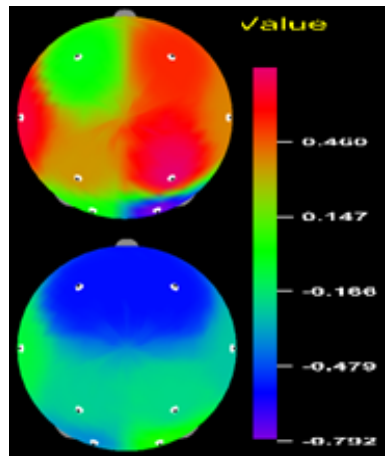

SEF50

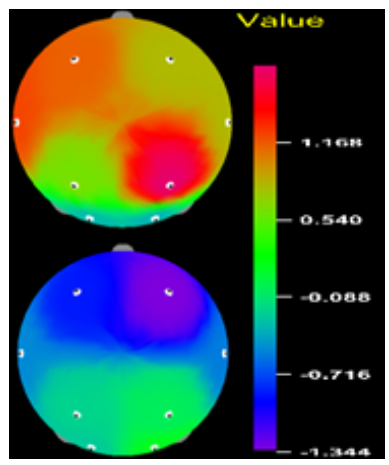

SEF90

Figure 3. Illustrations of Electroencephalography $(E E G)$ brain mapping for the participant from the individual activity type and participants from the group activity type before and after plant cultivating activity. Blue and red indicate low and high electrical potential, respectively. A: Value after plant cultivating activity minus value before the activity in an individual participant; B: Value after plant cultivating activity minus value before the activity in

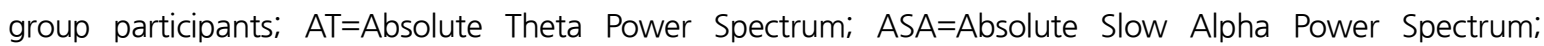
AFA=Absolute Fast Alpha Power Spectrum; ALB=Absolute Low Beta Power Spectrum; AMB=Absolute Mid Beta

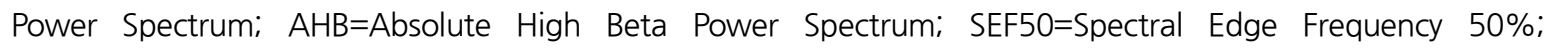
SEF90=Spectral Edge Frequency 90\%; Unit: AT, ASA, AFA, ALB, AMB, AHB: $\mu V^{2}$; SEF50, SEF90: Hz. 
participants who participated in group activities tended to be higher than those of the participants who participated in one-on-one activities, while their absolute high beta wave (AHB) and brain activities including spectral edge frequency (SEF) 50\% and SEF 90\% tended to be lower than those of the participants who participated in one-on-one activities (Tables 5 and 8, Figure 3). There was no statistical significance between the two types of activities, but the results can be interpreted that the activities tend to reduce the level of tension and stress. In addition, one-on-one activities provided participants with opportunities to feel a sense of closeness with an instructor and focused education, but group activities tended to be more effective in achieving stability and relaxation. Therefore, when tranquility is required in a stable and relaxed state, group activities seem to be more useful than one-on-one activities.

\section{Changes in the brain waves of participants before and after participating in one-on-one activities}

Changes in the brain waves of participants before and after participating in one-on-one activities of cultivating plants were compared. Absolute theta wave (AT) in the right frontal lobe (F4) after participating in one-on-one activities was lower than that before participating in one-on-one activities, and absolute fast alpha wave (AFA) in the left parietal lobe (P3) after participating in one-on-one activities was higher than that before participating in one-on-one activities, indicating that stability, relaxation and immersion were improved $(p<.05)$. The results were statistically significant (Tables 6 and 8, Figure 4). In addition, absolute low beta wave (ALB) was high in the right frontal lobe (F4), and absolute mid beta wave (AMB), an indicator of concentration that accompanies slight tension, was statistically significant high in the frontal lobes (F3, F4), right temporal lobe (T4), and right parietal lobe (P4) $(p<.05)$, indicating that one-on-one activities were effective in improving concentration. Absolute theta wave (AT), absolute fast alpha wave (AFA), absolute low beta wave (ALB) and absolute mid beta wave (AMB) increased after participating in activities of cultivating plants, which can be interpreted that the activities were effective in improving stability, relaxation, attention and concentration. These results are similar to those of earlier studies, including Kim et al. (2002) and Son et al. (1998, 1999), which found visual elements of plants increased the ratio of alpha wave and the activity of brain functions, and thus had a positive impact on phychophysiological conditions.

Table 6. Significance on the differences of brain waves in individual activity participant before/after plant cultivating activity

\begin{tabular}{lcccccccc}
\hline EEG $^{\mathrm{z}}$ & $\mathrm{F}^{\mathrm{y}}$ & $\mathrm{F} 4$ & $\mathrm{~T} 3$ & $\mathrm{~T} 4$ & $\mathrm{P} 3$ & $\mathrm{P} 4$ & $\mathrm{O} 1$ & $\mathrm{O} 2$ \\
\hline AT & -1.260 & $-1.400^{*}$ & -0.560 & -1.120 & -1.120 & -1.120 & -0.980 & -0.980 \\
ASA & -1.540 & -1.680 & -1.120 & -1.400 & -1.400 & -1.540 & -0.560 & -1.260 \\
AFA & -0.840 & -1.680 & -0.980 & -1.400 & $-0.980^{*}$ & -1.540 & -0.140 & -0.840 \\
SEF50 & -0.701 & -0.280 & -0.280 & -0.840 & -0.280 & -0.420 & -0.700 & -1.680 \\
ALB & -1.400 & $-2.240^{*}$ & -1.120 & -0.980 & -1.400 & -1.260 & -0.033 & 0.260 \\
AMB & $2.100^{*}$ & $-2.100^{*}$ & -0.980 & $-1.960^{*}$ & -1.540 & $-2.240^{*}$ & -0.560 & -0.420 \\
AHB & -1.400 & -1.260 & -1.120 & -0.560 & -1.680 & -1.820 & -0.420 & -0.420 \\
SEF90 & -0.420 & -0.280 & -0.140 & -0.980 & -0.338 & -0.560 & -0.420 & -0.980 \\
\hline
\end{tabular}

${ }^{\mathrm{z}}$ EEG=Electroencephalography; AT=Absolute Theta Power Spectrum; ASA=Absolute Slow Alpha Power Spectrum; AFA=Absolute Fast Alpha Power Spectrum; ALB=Absolute Low Beta Power Spectrum; AMB=Absolute Mid Beta Power Spectrum; AHB=Absolute High Beta Power Spectrum; SEF50=Spectral Edge Frequency 50\%; SEF90=Spectral Edge Frequency 90\%; Unit: AT, ASA, AFA, ALB, AMB, AHB: $\mu V 2$; SEF50, SEF90: Hz

${ }^{\mathrm{y}}$ See Figure 1. $\mathrm{F}=$ frontal lobes; $\mathrm{T}=$ temporal lobe; $\mathrm{P}=$ parietal lobes; $\mathrm{O}=\mathrm{occipital}$ lobes; odd and even numbers indicate left and right hemispheres, respectively.

${ }^{*} p<.05,{ }^{* *} p<.01$ by wilcoxon paired singed-rank test. 


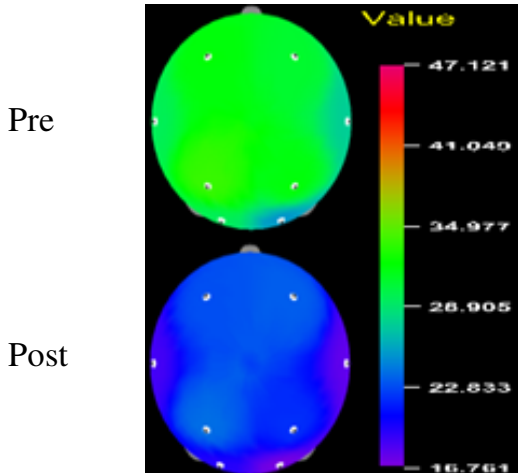

AT

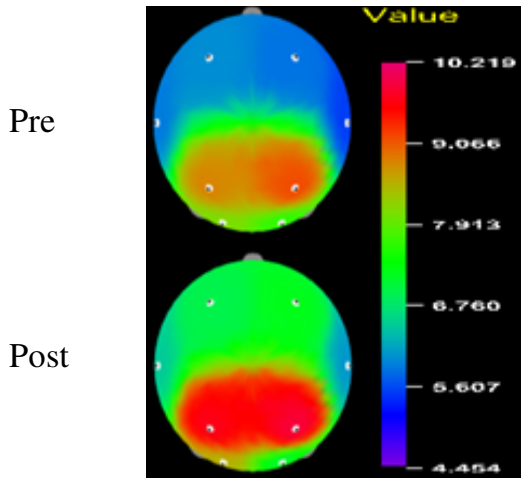

ALB

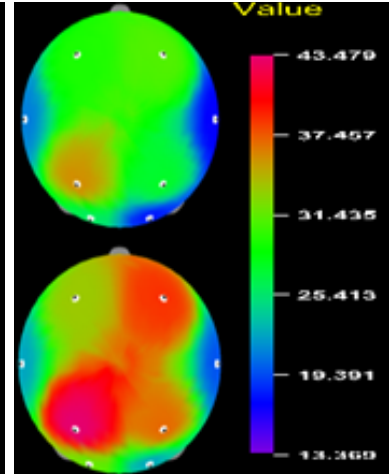

ASA

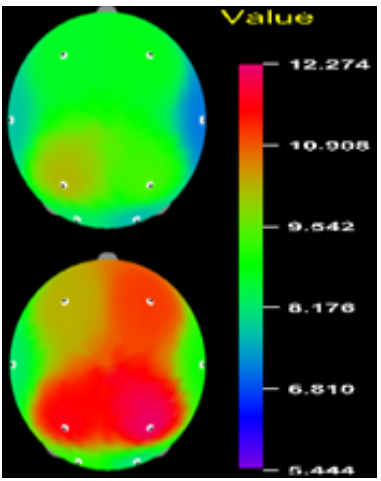

AMB

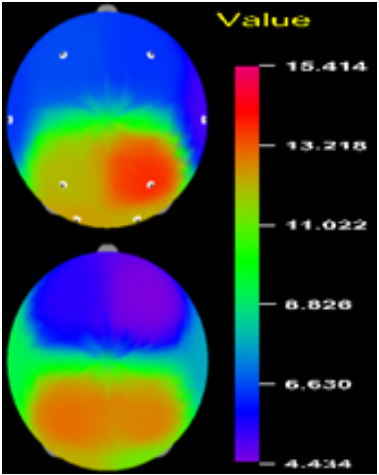

AFA

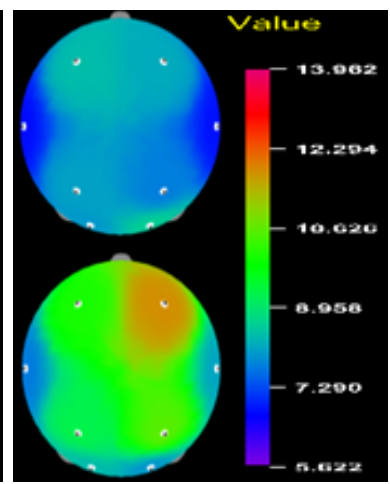

AHB

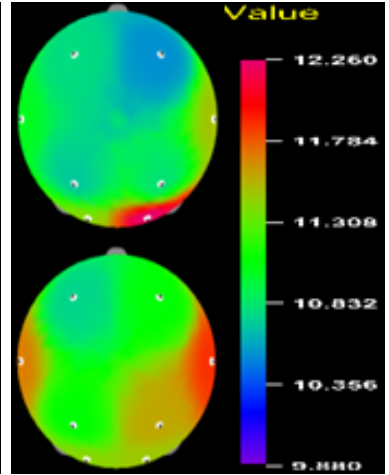

SEF50

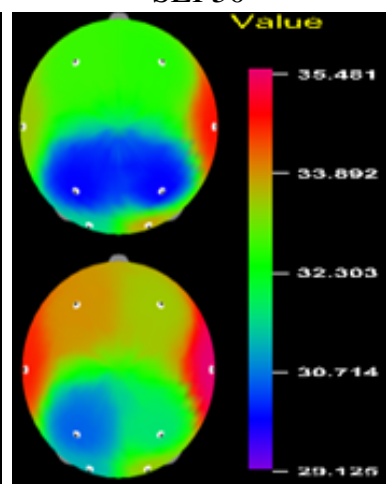

SEF90

Figure 4. Illustrations of Electroencephalography(EEG) brain mapping for the participant from individual activity type before and after plant cultivating activity. Blue and red indicate low and high electrical potential, respectively. Pre: Value before plant cultivating activity; Post: Value after plant growing activity; AT=Absolute Theta Power Spectrum; ASA=Absolute Slow Alpha Power Spectrum; AFA=Absolute Fast Alpha Power Spectrum; $\mathrm{ALB}=\mathrm{Absolute}$ Low Beta Power Spectrum; $\mathrm{AMB}=\mathrm{Absolute}$ Mid Beta Power Spectrum; $\mathrm{AHB}=\mathrm{Absolute}$ High Beta Power Spectrum; SEF50=Spectral Edge Frequency 50\%; SEF90=Spectral Edge Frequency 90\%; Unit: AT, ASA, AFA, ALB, AMB, AHB: $\mu V^{2}$; SEF50, SEF90: Hz.

\section{Changes in the brain waves of participants before and after participating in group activities}

Changes in the brain waves of participants before and after participating in group activities of cultivating plants were compared. Absolute theta wave (AT), an indicator of inner attention and concentration and emotional feelings such as pleasure and displeasure, in the left frontal lobe after participating in group activities was higher than that before participating in group activities. Absolute slow alpha wave (ASA) in the frontal lobes, temporal lobes, parietal lobes (P3, $\mathrm{P} 4)$ and left occipital lobe (O1) after participating in group activities was higher than that before participating in group activities, indicating that stability and relaxation were achieved without any stress or tension (Tables 7 and 8, Figure 5). Absolute fast alpha wave (AFA) was high in the frontal lobes and left temporal lobe (T3), but low in the right occipital lobe (O2), which shows that immersion from a rational perspective was high, but immersion from a visual perspective was low. In addition, absolute low beta wave (ALB) was high in the frontal lobes, temporal lobes, and left parietal lobe, while absolute mid beta wave (AMB) was high in all the measured 8 channels, which indicates that group activities increased attention and concentration, accompanying slight tension. These results were statistically significant $(p<.05)$. However, absolute high beta wave (AHB), an indicator of concentration that accompanies tension, was statistically significant high in the right frontal lobe, temporal lobes, parietal lobes and occipital lobes (Tables 7 and 8, Figure 5). The results can be 
Table 7. Significance on the differences of brain waves in group activity participants before/after plant cultivating activity

\begin{tabular}{lcccccccc}
\hline EEG $^{\mathrm{z}}$ & $\mathrm{F3}^{\mathrm{y}}$ & $\mathrm{F} 4$ & $\mathrm{~T} 3$ & $\mathrm{~T} 4$ & $\mathrm{P} 3$ & $\mathrm{P} 4$ & $\mathrm{O} 1$ & O2 \\
\hline AT & $-1.941^{*}$ & -2.277 & -1.605 & -1.643 & -1.829 & -1.904 & -1.456 & -1.456 \\
ASA & $-2.875^{*}$ & $-2.912^{* *}$ & $-2.651^{* *}$ & $-3.136^{* *}$ & $-2.725^{* *}$ & $-2.613^{* *}$ & $-2.016^{* *}$ & -1.419 \\
AFA & $-3.061^{*}$ & $-2.800^{* *}$ & $-0.055^{* *}$ & -1.904 & -2.277 & -1.381 & 2.688 & $-1.979^{*}$ \\
SEF50 & -1.269 & -0.896 & -0.224 & -0.448 & -0.784 & -0.541 & -0.187 & -0.672 \\
ALB & $-3.061^{*}$ & $-3.173^{* *}$ & $-2.763^{* *}$ & $-2.277^{*}$ & $-2.352^{*}$ & -1.904 & -1.867 & -2.165 \\
AMB & $-3.584^{*}$ & $-3.024^{* *}$ & $-3.285^{* *}$ & $-3.061^{* *}$ & $-3.547^{* *}$ & $-2.837^{* *}$ & $-2.315^{*}$ & $-2.912^{* *}$ \\
AHB & -1.419 & $-2.128^{* *}$ & $-3.099^{* *}$ & $-2.763^{* *}$ & $-2.763^{* *}$ & $-2.464^{*}$ & $-2.352^{*}$ & $-2.576^{* *}$ \\
SEF90 & -0.597 & -1.904 & -0.112 & -0.635 & -0.037 & -0.299 & -0.187 & -0.411 \\
\hline
\end{tabular}

${ }^{\mathrm{z}}$ EEG=Electroencephalography; AT=Absolute Theta Power Spectrum; ASA=Absolute Slow Alpha Power Spectrum; AFA=Absolute Fast Alpha Power Spectrum; ALB=Absolute Low Beta Power Spectrum; AMB=Absolute Mid Beta Power Spectrum; AHB=Absolute High Beta Power Spectrum; SEF50=Spectral Edge Frequency 50\%; SEF90=Spectral Edge Frequency 90\%; Unit: AT, ASA, AFA, ALB, AMB, AHB: $\mu V^{2}$; SEF50, SEF90: Hz

${ }^{\mathrm{y}}$ See Figure 1. $\mathrm{F}=$ frontal lobes; $\mathrm{T}=$ temporal lobe; $\mathrm{P}=$ parietal lobes; $\mathrm{O}=\mathrm{occipital}$ lobes; odd and even numbers indicate left and right hemispheres, respectively.

${ }^{*} p<.05,{ }^{* *} p<.01$ by wilcoxon paired singed-rank test.

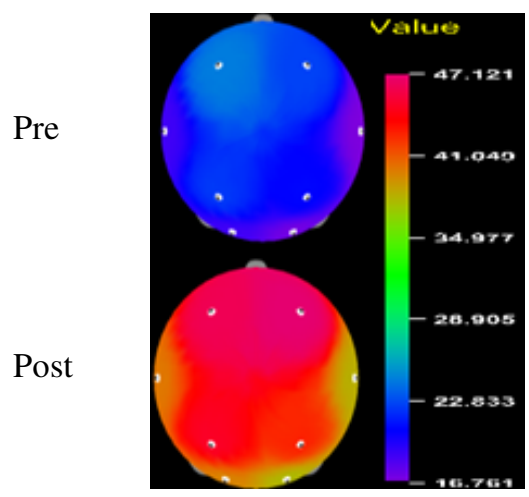

AT

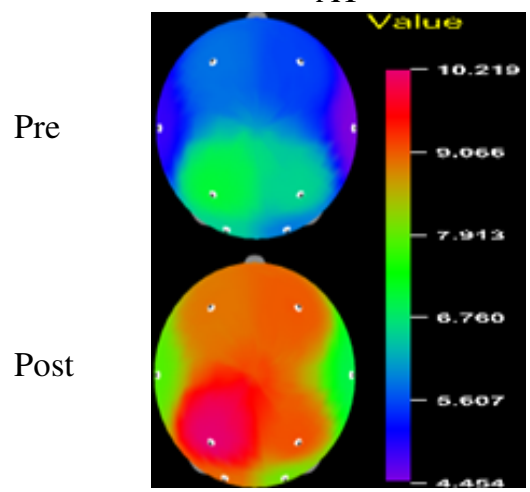

ALB

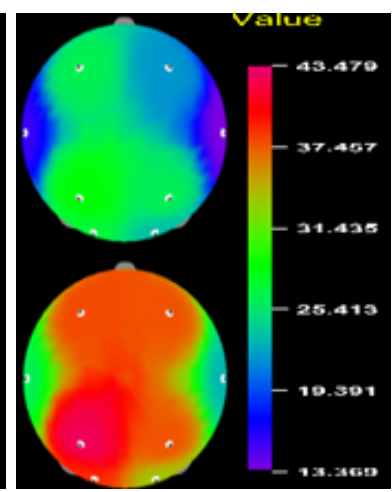

ASA

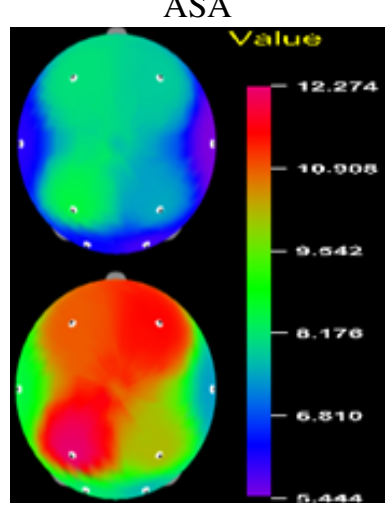

$\mathrm{AMB}$

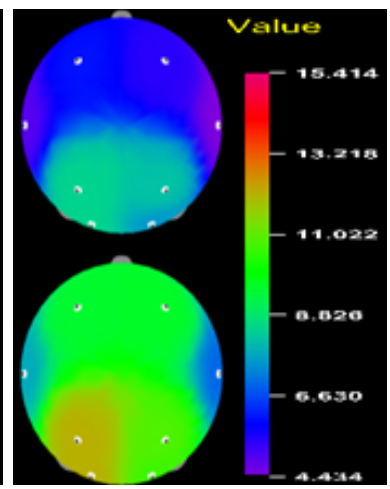

AFA

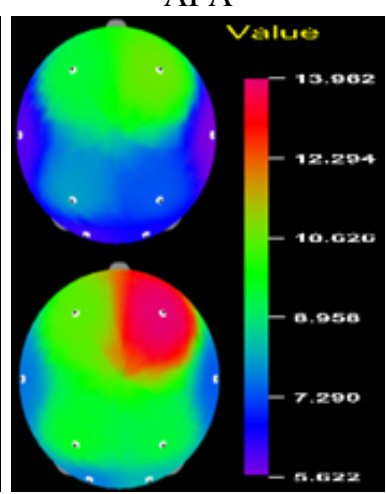

AHB

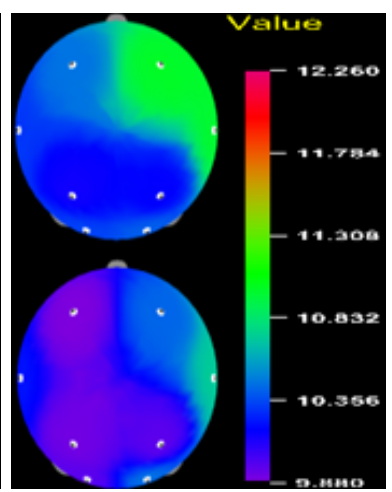

SEF50

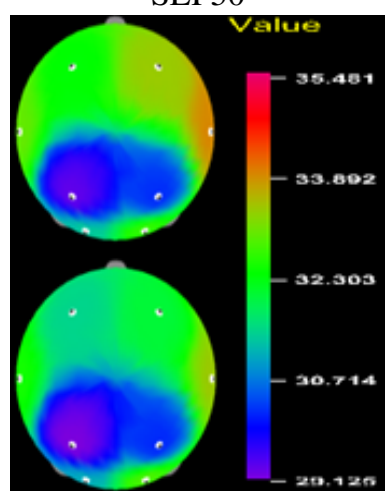

SEF90

Figure 5. Illustrations of Electroencephalography(EEG) brain mapping for participants from the group activity type before and after plant cultivating activity. Blue and red indicate low and high electrical potential, respectively. Pre: Value before plant cultivating activity; Post: Value after plant cultivating activity; AT=Absolute Theta Power Spectrum; ASA=Absolute Slow Alpha Power Spectrum; AFA=Absolute Fast Alpha Power Spectrum; $\mathrm{ALB}=$ Absolute Low Beta Power Spectrum; $\mathrm{AMB}=\mathrm{Absolute}$ Mid Beta Power Spectrum; $\mathrm{AHB}=\mathrm{Absolute}$ High Beta Power Spectrum; SEF50=Spectral Edge Frequency 50\%; SEF90=Spectral Edge Frequency 90\%; Unit: AT, ASA, AFA, ALB, AMB, AHB: jV2; SEF50, SEF90: Hz. 
Table 8. Brain waves of participants in individual and group activity before/after plant cultivating activity

\begin{tabular}{|c|c|c|c|c|c|c|c|c|c|}
\hline $\mathrm{EEG}^{\mathrm{z}}$ & Treatment & $F 3^{y}$ & F4 & $\mathrm{T} 3$ & $\mathrm{~T} 4$ & P3 & P4 & $\mathrm{O} 1$ & $\mathrm{O} 2$ \\
\hline \multirow{4}{*}{ AT } & $\mathrm{Ib}^{\mathrm{x}}$ & $31.945 \pm 49.59^{w}$ & $30.827 \pm 47.48$ & $29.572 \pm 50.36$ & $27.607 \pm 50.72$ & $33.878 \pm 55.18$ & $31.921 \pm 54.17$ & $29.550 \pm 51.68$ & $25.302 \pm 45.64$ \\
\hline & $\mathrm{Gb}$ & $24.384 \pm 27.51$ & $22.573 \pm 25.68$ & $18.672 \pm 23.94$ & $16.761 \pm 25.34$ & $22.288 \pm 25.11$ & $20.784 \pm 26.49$ & $18.671 \pm 22.10$ & $17.169 \pm 22.51$ \\
\hline & Ia & $22.973 \pm 12.28$ & $23.396 \pm 12.98$ & $18.597 \pm 10.96$ & $17.751 \pm 12.05$ & $23.954 \pm 13.01$ & $21.981 \pm 12.65$ & $19.549 \pm 11.85$ & $17.057 \pm 11.79$ \\
\hline & $\mathrm{Ga}$ & $46.193 \pm 75.05$ & $47.125 \pm 75.56$ & $40.082 \pm 74.86$ & $38.154 \pm 75.31$ & $44.930 \pm 76.49$ & $42.748 \pm 76.40$ & $39.764 \pm 74.55$ & $37.76 \pm 75.38$ \\
\hline \multirow{4}{*}{ ASA } & $\mathrm{Ib}$ & $29.481 \pm 29.37$ & $31.061 \pm 32.20$ & $21.046 \pm 17.72$ & $17.021 \pm 15.11$ & $35.769 \pm 31.57$ & $27.435 \pm 25.43$ & $25.926 \pm 10.85$ & $17.850 \pm 10.36$ \\
\hline & $\mathrm{Gb}$ & $26.296 \pm 18.30$ & $21.825 \pm 18.35$ & $15.493 \pm 9.87$ & $13.369 \pm 9.60$ & $28.547 \pm 19.07$ & $26.077 \pm 19.65$ & $27.024 \pm 22.70$ & $23.423 \pm 16.93$ \\
\hline & Ia & $33.437 \pm 34.94$ & $38.643 \pm 40.13$ & $22.398 \pm 20.03$ & $19.702 \pm 16.08$ & $43.481 \pm 47.84$ & $37.004 \pm 41.25$ & $31.776 \pm 22.50$ & $22.557 \pm 15.15$ \\
\hline & $\mathrm{Ga}$ & $38.012 \pm 37.41$ & $37.731 \pm 4.97$ & $26.155 \pm 31.23$ & $23.020 \pm 28.69$ & $42.703 \pm 39.63$ & $37.650 \pm 36.30$ & $38.944 \pm 42.39$ & $33.678 \pm 37.50$ \\
\hline \multirow{4}{*}{ AFA } & $\mathrm{Ib}$ & $6.610 \pm 3.63$ & $6.363 \pm 3.71$ & $6.383 \pm 2.97$ & $5.099 \pm 2.50$ & $12.082 \pm 6.53$ & $13.729 \pm 13.57$ & $12.406 \pm 12.78$ & $12.223 \pm 14.34$ \\
\hline & $\mathrm{Gb}$ & $5.999 \pm 3.87$ & $5.393 \pm 4.04$ & $4.891 \pm 3.14$ & $4.434 \pm 2.77$ & $8.447 \pm 6.75$ & $8.140 \pm 7.61$ & $8.482 \pm 8.81$ & $7.558 \pm 6.59$ \\
\hline & Ia & $7.207 \pm 3.58$ & $7.452 \pm 3.43$ & $6.504 \pm 2.54$ & $6.148 \pm 2.47$ & $13.367 \pm 8.54$ & $15.416 \pm 14.53$ & $12.502 \pm 11.20$ & $11.686 \pm 13.31$ \\
\hline & $\mathrm{Ga}$ & $9.535 \pm 11.14$ & $9.603 \pm 12.42$ & $7.778 \pm 10.06$ & $6.953 \pm 9.09$ & $12.170 \pm 12.70$ & $10.854 \pm 12.20$ & $12.169 \pm 13.57$ & $10.655 \pm 12.28$ \\
\hline \multirow{4}{*}{ SEF50 } & $\mathrm{Ib}$ & $10.780 \pm 2.17$ & $10.530 \pm 1.91$ & $11.017 \pm 2.80$ & $11.492 \pm 3.19$ & $10.712 \pm 1.98$ & $10.813 \pm 2.15$ & $11.404 \pm 3.48$ & $12.260 \pm 4.42$ \\
\hline & $\mathrm{Gb}$ & $10.454 \pm 2.99$ & $10.995 \pm 3.54$ & $10.309 \pm 1.52$ & $10.976 \pm 2.38$ & $10.146 \pm 1.35$ & $10.175 \pm 1.46$ & $10.336 \pm 1.35$ & $10.402 \pm 1.62$ \\
\hline & Ia & $10.757 \pm 1.49$ & $11.074 \pm 1.66$ & $11.698 \pm 2.98$ & $11.885 \pm 2.55$ & $11.072 \pm 2.08$ & $11.585 \pm 1.97$ & $11.425 \pm 3.23$ & $11.469 \pm 3.18$ \\
\hline & $\mathrm{Ga}$ & $9.880 \pm 2.29$ & $10.419 \pm 39.2$ & $10.220 \pm 2.39$ & $10.718 \pm 2.81$ & $9.914 \pm 1.40$ & $9.963 \pm 1.61$ & $9.966 \pm 1.48$ & $10.446 \pm 2.10$ \\
\hline \multirow{4}{*}{ ALB } & $\mathrm{Ib}$ & $6.016 \pm 2.63$ & $5.848 \pm 2.73$ & $5.896 \pm 2.30$ & $5.527 \pm 2.73$ & $8.805 \pm 3.73$ & $9.158 \pm 4.82$ & $8.092 \pm 4.79$ & $7.646 \pm 5.39$ \\
\hline & $\mathrm{Gb}$ & $5.829 \pm 2.90$ & $5.547 \pm 2.65$ & $4.885 \pm 2.29$ & $4.454 \pm 1.86$ & $7.075 \pm 4.21$ & $6.566 \pm 4.46$ & $6.533 \pm 5.10$ & $5.896 \pm 4.24$ \\
\hline & Ia & $6.967 \pm 2.36$ & $7.232 \pm 2.39$ & $6.489 \pm 2.20$ & $6.086 \pm 1.96$ & $9.713 \pm 3.74$ & $9.907 \pm 4.07$ & $8.500 \pm 5.07$ & $7.148 \pm 4.64$ \\
\hline & $\mathrm{Ga}$ & $8.906 \pm 9.47$ & $9.087 \pm 9.57$ & $7.849 \pm 9.43$ & $6.984 \pm 8.44$ & $10.222 \pm 11.25$ & $9.132 \pm 9.59$ & $8.988 \pm 10.99$ & $8.036 \pm 8.90$ \\
\hline \multirow{4}{*}{ AMB } & $\mathrm{Ib}$ & $8.688 \pm 3.18$ & $8.757 \pm 3.07$ & $7.783 \pm 3.53$ & $7.149 \pm 3.12$ & $10.201 \pm 4.47$ & $9.371 \pm 3.65$ & $8.257 \pm 2.91$ & $7.691 \pm 3.84$ \\
\hline & $\mathrm{Gb}$ & $8.103 \pm 3.35$ & $7.858 \pm 3.73$ & $6.057 \pm 2.45$ & $5.444 \pm 1.96$ & $8.502 \pm 4.02$ & $7.501 \pm 3.15$ & $6.238 \pm 2.72$ & $5.862 \pm 2.56$ \\
\hline & Ia & $10.256 \pm 3.66$ & $11.126 \pm 4.58$ & $8.241 \pm 1.94$ & $8.990 \pm 4.18$ & $11.636 \pm 3.72$ & $12.184 \pm 4.84$ & $9.177 \pm 3.10$ & $8.153 \pm 3.26$ \\
\hline & $\mathrm{Ga}$ & $10.919 \pm 6.07$ & $11.477 \pm 7.44$ & $8.504 \pm 4.70$ & $7.426 \pm 4.07$ & $12.276 \pm 7.88$ & $10.175 \pm 5.32$ & $8.165 \pm 5.32$ & $7.673 \pm 4.01$ \\
\hline \multirow{4}{*}{ AHB } & $\mathrm{Ib}$ & $8.383 \pm 1.98$ & $8.173 \pm 1.92$ & $6.786 \pm 1.72$ & $6.821 \pm 2.01$ & $8.081 \pm 2.30$ & $7.740 \pm 2.14$ & $8.000 \pm 3.00$ & $8.601 \pm 6.36$ \\
\hline & $\mathrm{Gb}$ & $9.449 \pm 6.54$ & $10.737 \pm 10.29$ & $5.969 \pm 2.41$ & $5.622 \pm 2.13$ & $8.045 \pm 3.21$ & $7.371 \pm 2.98$ & $6.179 \pm 2.15$ & $6.537 \pm 3.54$ \\
\hline & Ia & $10.047 \pm 4.43$ & $11.833 \pm 8.91$ & $7.702 \pm 1.86$ & $8.113 \pm 3.81$ & $9.260 \pm 2.48$ & $10.608 \pm 5.88$ & $8.356 \pm 3.17$ & $7.960 \pm 3.63$ \\
\hline & $\mathrm{Ga}$ & $10.590 \pm 8.41$ & $13.967 \pm 16.84$ & $7.683 \pm 4.49$ & $7.413 \pm 4.66$ & $9.624 \pm 4.87$ & $9.385 \pm 6.53$ & $7.740 \pm 3.96$ & $8.319 \pm 4.72$ \\
\hline \multirow{4}{*}{ SEF90 } & $\mathrm{Ib}$ & $32.753 \pm 5.33$ & $32.625 \pm 4.92$ & $33.440 \pm 6.11$ & $34.746 \pm 6.91$ & $29.943 \pm 4.73$ & $29.890 \pm 5.57$ & $31.454 \pm 7.12$ & $33.760 \pm 7.97$ \\
\hline & $\mathrm{Gb}$ & $32.372 \pm 5.74$ & $33.405 \pm 5.70$ & $33.033 \pm 4.47$ & $33.978 \pm 5.22$ & $29.321 \pm 3.71$ & $30.225 \pm 4.88$ & $31.352 \pm 5.69$ & $32.720 \pm 5.66$ \\
\hline & Ia & $33.901 \pm 4.13$ & $33.447 \pm 5.35$ & $34.670 \pm 5.65$ & $35.576 \pm 6.14$ & $30.569 \pm 6.03$ & $31.689 \pm 6.03$ & $31.139 \pm 6.01$ & $33.407 \pm 6.92$ \\
\hline & $\mathrm{Ga}$ & $31.504 \pm 6.12$ & $32.060 \pm 7.05$ & $32.526 \pm 6.64$ & $33.421 \pm 7.02$ & $29.125 \pm 5.70$ & $30.192 \pm 6.14$ & $31.107 \pm 6.82$ & $32.883 \pm 6.96$ \\
\hline
\end{tabular}

${ }^{\mathrm{z}}$ EEG=Electroencephalography; AT=Absolute Theta Power Spectrum; ASA=Absolute Slow Alpha Power Spectrum; AFA=Absolute Fast Alpha Power Spectrum; ALB=Absolute Low Beta Power Spectrum; AMB=Absolute Mid Beta Power Spectrum; AHB=Absolute High Beta Power Spectrum; SEF50=Spectral Edge Frequency 50\%; SEF90=Spectral Edge Frequency 90\%; Unit: AT, ASA, AFA, ALB, AMB, AHB: $\mu \mathrm{V}^{2}$; SEF50, SEF90: Hz

${ }^{\mathrm{y}}$ See Figure 1. $\mathrm{F}=$ frontal lobes; $\mathrm{T}=$ temporal lobe; $\mathrm{P}=$ parietal lobes; $\mathrm{O}=\mathrm{occipital}$ lobes; odd and even numbers indicate left and right hemispheres, respectively.

${ }^{\mathrm{x}} \mathrm{Ib}=$ Individual before activity; $\mathrm{Gb}=$ Group before activity; $\mathrm{Ia}=$ Individual after activity; $\mathrm{Ga}=\mathrm{Group}$ after activity.

${ }^{\mathrm{w}}$ Mean \pm standard deviation.

interpreted that the activities of cultivating plants were effective in improving physiological conditions including stability and relaxation, and increasing immersion, attention and concentration in a proper arousal state, and that tension is accompanied while concentrating.

\section{Changes in the autonomic nervous system of participants by activity type (one-on-one vs group)}

Changes in the heart rate of participants who participated in one-on-one and group activities were compared. The heart rate of those who participated in group activities was statistically significantly lower than that of those who participated in one-on-one activities $(p<.05)$ (Figure 6). However, there was no statistically significant difference in the activity of the 


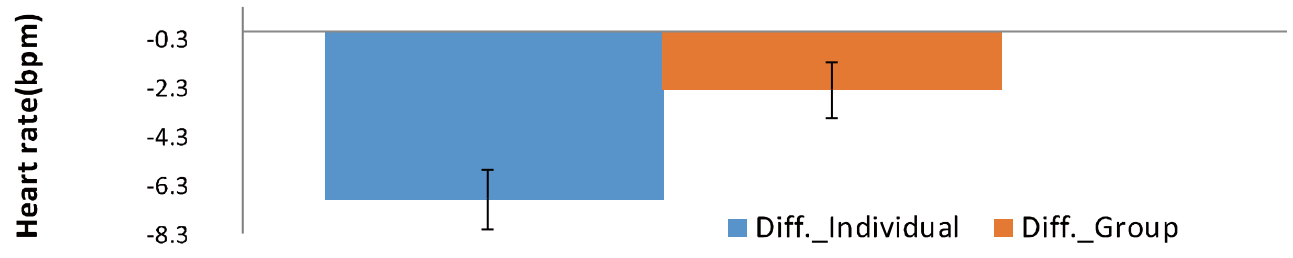

Figure 6. Differences in heart rate for individual participant and group participants between before and after plant cultivating activity.

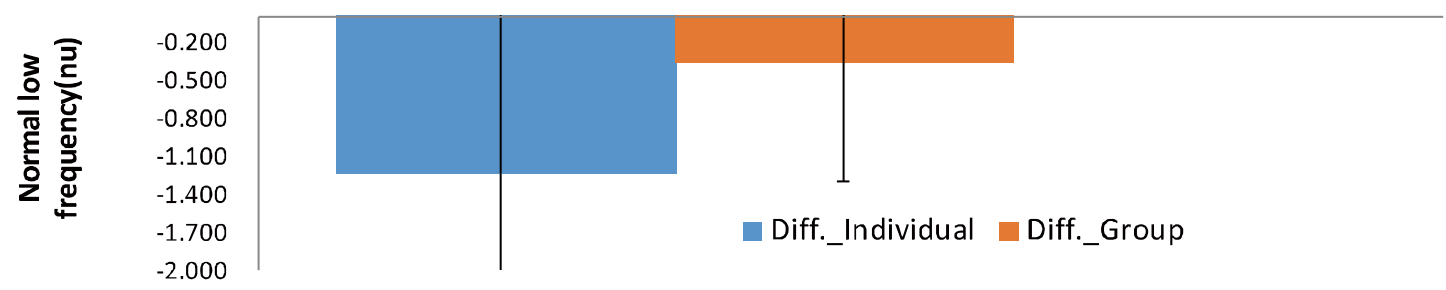

Figure 7. Differences in parasympathetic nerve for individual participant and group participants between before and after plant cultivating activity.

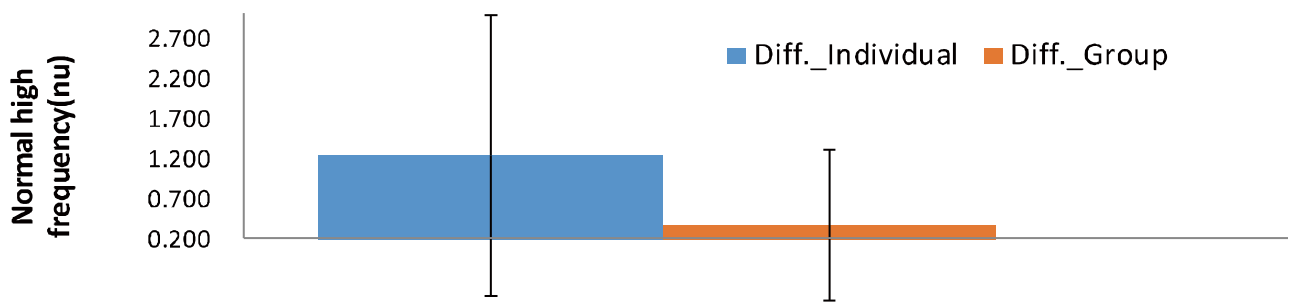

Figure 8. Differences in sympathetic nerve for individual participant and group participants between before and after plant cultivating activity.

Table 9. Pulse changes in individual participant and group participants before and after plant cultivating activity

\begin{tabular}{cccccc}
\hline \multirow{2}{*}{ Pulse } & Activity type & Before & After & $\mathrm{t}$ & $p$ \\
\hline \multirow{2}{*}{ Total } & Individual & $72.1 \pm 10.5^{z}$ & $68.0 \pm 8.8$ & 2.146 & .690 \\
& Group & $71.5 \pm 9.10$ & $66.7 \pm 6.4$ & 4.274 & .01 \\
\hline
\end{tabular}

${ }^{\mathrm{z}}$ Values are mean \pm standard deviation.

Table 10. Blood pressure changes in individual participant and group participants before and after plant cultivating activity

\begin{tabular}{|c|c|c|c|c|c|}
\hline Blood pressure & Activity type & Before & After & $\mathrm{t}$ & $p$ \\
\hline \multicolumn{6}{|c|}{ Systolic blood pressure } \\
\hline \multirow{2}{*}{ Total } & Individual & $101.5 \pm 13.7^{\mathrm{z}}$ & $103.9 \pm 15.2$ & -1.297 & 236 \\
\hline & Group & $103.6 \pm 11.6$ & $104.2 \pm 11.6$ & -0.581 & .567 \\
\hline \multicolumn{6}{|c|}{ Diastolic blood pressure } \\
\hline \multirow{2}{*}{ Total } & Individual & $69.3 \pm 10.2$ & $73.8 \pm 6.0$ & -2.097 & .074 \\
\hline & Group & $72.3 \pm 8.7$ & $72.1 \pm 9.0$ & 0.199 & .844 \\
\hline
\end{tabular}

${ }^{\mathrm{z}}$ Values are mean \pm standard deviation. 
sympathetic nervous system (Figure 7) and parasympathetic nervous system (Figure 8) among the activities of the autonomic nervous system, between the two activity types.

\section{Changes in the pulse and blood pressure of participants by activity type (one-on-one vs group)}

Changes in the pulse of participants who participated in one-on-one and group activities were compared. The pulse of those who participated in one-on-one activities decreased by 4.1 on average from 72.1 before the activities to 68.0 after the activities, but the decrease was not statistically significant. However, there was a statistically significant difference in the pulse of those who participated in group activities before and after participating in group activities $(\mathrm{t}=4.274, p<.01)$ (Table 9). Changes in the blood pressure of participants before and after participating in activities of cultivating plants were compared, but there was no statistically significant difference (Table 10). The results can be interpreted that the activities of cultivating activities are effective in achieving relaxation.

\section{Conclusion}

In order to examine changes in the physiological conditions of those who participated in plant cultivating activities, the electroencephalography (EEG) and electrocardiogram (ECG) of female parents of an elementary school student in their $30 \mathrm{~s}$ and $40 \mathrm{~s}$ were measured before and after participating in the program of plant cultivating activities once a week, a total of 10 sessions. In each session, one person who participated in one-on-one activities and three participants selected out of 26 persons who participated in group activities, a total of 4 participants, were tested. The three selected participants were tested at the same time using three EEG and ECG monitors. The alpha and beta waves of the entire participants after participating in plant cultivating activities were higher than before participating in the activities, which indicates that the activities increase the activity of the brain. Absolute slow alpha wave (ASA), absolute fast alpha wave (AFA), absolute low beta wave (ALB), and absolute mid beta wave (AMB) were increased after participating in plant cultivating activities, and these results can be interpreted that the activities were effective in improving physiologically conditions, including stability and relaxation, as well as immersion, attention and concentration in a proper arousal state. However, absolute high beta wave (AHB) was also increased. The result can be interpreted that activities of touching and feeling plants improved attention and concentration, allowed participants to actively acquire information on things and significantly improved their concentration. At the same time, however, these active brain activities accompanied tension. Changes in the physiological conditions of those who participated in one-on-one and group activities were compared, but there was no statistically significant difference between those who participated in one-on-one activities and those who participated in group activities. In addition, changes in the brain waves of participants by activity type (one-on-one and group) before and after participating in activities were compared. Absolute theta wave (AT) after participating in one-on-one activities was low in the right frontal lobe (F4), and absolute fast alpha wave (AFA) was high in the left parietal lobe (P3), showing high immersion $(p<.05)$. Absolute low beta wave (ALB), an indicator of attention that accompanies arousal, was high in the right frontal lobe, while absolute mid beta wave (AMB), an indicator of concentration that accompanies slight tension, was statistically significantly high in the frontal lobes (F3, F4), right temporal lobe (T4), and right parietal lobe (P4), indicating that participating in one-on-one activities was effective in improving concentration $(p<.05)$. Absolute theta wave (AT) after participating in group activities was high in the left frontal lobe, while absolute slow alpha wave (ASA) was high in most of the measured spots, indicating that participating in group activities was effective in achieving stability and relaxation with almost no stress or tension. Absolute fast alpha wave (AFA) was high in the frontal lobes and left temporal lobe (T3), but low in the right occipital lobe $(\mathrm{O} 2)$, which indicates that immersion from a rational perspective was high, but 
immersion from a visual perspective was low. Absolute low beta wave (ALB), absolute mid beta wave (AMB) and absolute high beta wave (AHB) were statistically significantly high in most of the measured spots. In addition, when comparing those who participated in one-on-one activities of cultivating plants with those who participated in group activities of cultivating plants, the heart rate of those who participated in one-on-one activities was statistically significantly lower than that of those who participated in group activities, but the heart rate of all the participants was within the average range. These results can be interpreted that activities of cultivating plants are effective in achieving physiological stability and relaxation and improving immersion, attention and concentration in a proper arousal state.

\section{References}

Bang, K.S. 2004. Maternal child-rearing attitude, child-rearing burden, and their preschoolers' temperament. J. Korean Soc. Matern. Child Health 8(1):77-87.

Becker, W.C. 1964. Consequences of different kinds of parental discipline. In: M.L. Hoffman \& L.W. Hoffman(Eds.), Review of child development research (pp. 169-208). New York, NY: Russell Sage Foundation.

Berger, H. 1929. Über das elektrekephalogram des menschen (On the human electrocephalogram). Archiv für psychiatrie und nervenkrankheiten 87:527-570.

Cho, B.W. 2006. Development of daily hassles scale and daily hassles coping behaviors scale for elementary school children. Korean J. Child Educ. 15(3):5-21.

Choi, Y.A. and J.G. Seo. 2007. Developing horticultural therapy program and its effect for reducing parenting stress. J. Korean Soc. People Plants Environ. 10(3):90-95.

Davis, M. and E. Emory. 1995. Sex differences in neonatal stress reactivity. Child Dev. 66(1):14-27. DOI:10.1111/j.1467-8624.1995.tb00852.x

Hwang, H.J., Y.A. Lee, J.E. Song, and K.C. Son. 2007. Effect of horticultural therapy based upon reality therapy on the reduction of depression, the change in parental sense of competence, and stress coping types of elementary student's mother. Korean J. Hortic. Sci. Technol. 25(3):268-276.

Jang, H.S., G.M. Gim, S.J. Jeong, and J.S. Kim. 2018. Effects of plant cultivating activity for reducing parental stress. J. People Plants Environ. 21(3):203-211. DOI:10.11628/ksppe.2018.21.3.203

Jang, H.S., G.M. Gim, K.J. Kim, and H.H. Jung. 2017. Change of physiology and emotion according to plant -decoration activity in workers. J. People Plants Environ. 20(5):555-566. DOI:10.11628/ksppe.2017.20.5. 555

Kaplan, R. 2001. The nature of the view from home: Psychological benefits. Environ. Behav. 33(4):507-542. DOI:10.1177/00139160121973115

Kim, E.I., S.H. Hwang, W.S. Shin, and K.W. Ahn. 2002. Physiological effect of forest types: Focused on brain wave and pulsation. J. Korean Inst. For. Recreat. 6(2):43-48.

Kim, S.Y. 2001. Effect of horticultural therapy on the functional rehabilitation in hemiplegic patients after stroke. Master's thesis, Konkuk University, Seoul, Korea.

Lee, E.D., S.J. Park, R.H. Yoo, and S.J. Hong. 2011. Analysis on the activity contents of forest healing programs in Korea. J. Korean Inst. For. Recreat. 15(2):101-109.

Lee, J.H., W.S. Shin, P.S. Yeoun, and R.W. Yoo. 2009. The influence of forest scenes on psychophysiological responses. J. Korean For. Soc. 98(1):88-93.

Matsuo, E. 2008. Humanity in horticulture-healing and pleasure. Acta Hortic. 790:39-44. DOI:10.17660/ActaHortic.2008.790.3

McKenzie-Mohr, D., L.S. Nemiroff, L. Beers, and S. Desmarais. 1995. Determinants of responsible environmental behavior. J. Soc. Issues 51(4):139-156. DOI:10.1111/j.1540-4560.1995.tb01352.x

Park, B.H., S.K. Kim, S.M. Kim, S.B. Yoon, and M.J. Park. 2013. Studies for using type and benefits of the visitors in the natural recreation forest. J. Korean Inst. For. Recreat. 17(4):59-67. 
Park, S.M., J.M. Woo, W. Kim, and Y.J. Lee. 2012. Sub-populations and disorders that can be applied to forest therapy. J. Korean Inst. For. Recreat. 16(1):35-42.

Relf, P.D. 1990. Psychological and sociological response to plants: Implications for horticulture. HortScience 25(1):11-13.

Shin, S.J. 1997. Effects of stress, social support and efficacy on mothers' parenting behaviors. Doctoral dissertation, Yonsei University, Seoul, Korea.

Shin, W.S., P.S. Yeoun, and J.H. Lee. 2007. The impact that a forest experience influences on a human mental state stability. JJ. Korean Inst. For. Recreat. 11(3):37-43.

Son, K.C., S.Y. Kim, S.S. Lee, J.E. Song, and M.K. Cho. 2006. Programs and assessment tools for the professional horticultural therapy. Seoul, Korea: KU Book.

Son, K.C., J.S. Lee, and J.E. Song. 1998. Effect of visual recognition of indoor plants on changes of human brain electroencephalography. J. Korean Soc. Hortic. Sci. 39(6):858-862.

Son, K.C., J.S. Lee, and J.E. Song. 1999. Effect of visual recognition of Ficus benjamina and its photograph on changes of human brain electroencephalography and brain blood flow. J. Korean Soc. Hortic. Sci. 40(1):134-138.

Ulrich, R.S. 1984. View through a window may influence recovery from surgery. Science 224(4647):420-421. DOI:10.1126/science.6143402 